Maya K. Spillmann • A.J. Willem Van der Does

Meridith A. Rankin - Rachel D. Vuolo

Jonathan E. Alpert $\cdot$ Andrew A. Nierenberg

Jerrold F. Rosenbaum - Douglas Hayden

David Schoenfeld $\cdot$ Maurizio Fava

\title{
Tryptophan depletion in SSRI-recovered depressed outpatients
}

Received: 7 September 1999 / Accepted: 13 November 2000 / Published online: 28 March 2001

(C) Springer-Verlag 2001

\begin{abstract}
Rationale: Recently, a number of studies have challenged the finding that acute tryptophan depletion (TD) increases depressive symptoms in medicated, formerly depressed patients. The present study examined the effects of acute nutritional TD on remitted depressed patients currently treated with selective serotonin reuptake inhibitors. In an attempt to clarify conflicting earlier findings, the effects of a number of clinical variables on outcome were also investigated. Methods: Ten patients underwent TD in a double-blind, controlled, balanced crossover fashion. The control session followed the procedure of Krahn et al. (1996 Neuropsychopharmacology 15:325-328). Sessions were 5-8 days apart. Results: TD was significantly related to increased scores on clinicianrated depression and anxiety scales, and on self-rated depression, anxiety, and somatic symptoms. The control challenge had no effect, despite the fact that the reductions in plasma tryptophan during the control session were unexpectedly high. Some evidence was found for a threshold in the relationship between reduction of plasma tryptophan and mood response. Conclusions: The mood effect of TD in medicated, formerly depressed patients was confirmed. A threshold may exist for mood effects following TD, implying that recent negative findings may have been caused by insufficient depletion. No other predicting or mediating factors were identified, although the variable "history of response pattern to medication" deserves further study.
\end{abstract}

M.K. Spillmann · A.J.W. Van der Does · M.A. Rankin

R.D. Vuolo · J.E. Alpert · A.A. Nierenberg · J.F. Rosenbaum

D. Hayden · D. Schoenfeld · M. Fava (国)

Depression Clinical and Research Program,

Massachusetts General Hospital - WAC 812, 15 Parkman Street,

Boston, MA 02114, USA

e-mail: Mfava@partners.org

Fax: +1-617-7267541

A.J.W. Van der Does

Departments of Psychology and Psychiatry, Leiden University,

Leiden, The Netherlands
Keywords Tryptophan depletion · Depression Antidepressant $\cdot$ Remission $\cdot$ Mood effect

\section{Introduction}

The tryptophan depletion (TD) challenge is a useful model for studying brain serotonin function. Reducing tryptophan availability to the brain impairs serotonin synthesis due to the dependence of CNS serotonin synthesis on plasma levels of its amino acid precursor, tryptophan (Biggio et al. 1974; Carpenter et al. 1998). Nutritional TD has been shown to cause depressive symptoms in remitted depressed patients on antidepressant treatment (Delgado et al. 1990; Smith et al. 1997). The probability of a TD-induced symptom exacerbation is highest in patients who were treated with antidepressants affecting the serotonergic system [selective serotonin reuptake inhibitors (SSRIs); Delgado et al. 1991, 1999]. Certain other psychiatric syndromes also seem vulnerable to symptom exacerbation following TD (Van der Does 2000a).

It should be noted, however, that even in SSRI-treated patients, TD causes clinically significant symptoms in not more than $50-60 \%$ of patients (see Van der Does 2000a for a review). Furthermore, a number of studies have been published in which relapse rates during TD were much lower (Bremner et al. 1997; Aberg-Wistedt et al. 1998). One study (Moore et al. 1998) even found no mood effects. Variables that have been related to response to TD include time since remission (Moore et al. 1998) and history of suicidal tendencies (Leyton et al. 1997). However, support for these variables is weak or inconsistent (Van der Does 2000a). The current study further investigated possible correlates and predictors of the effects of acute nutritional TD in remitted depressed patients. Variables that were examined were duration of remission of depressive symptoms, pattern of response to antidepressant treatment ("true drug pattern" vs "placebo pattern"), and number of previous episodes of major depression. 


\section{Materials and methods}

\section{Subjects}

Eligible subjects were outpatients between the ages of 18 and 65 years with a history of major depressive disorder. At the time of enrollment, patients had to be in remission following treatment with an SSRI. Pretreatment diagnoses were ascertained using the Structured Clinical Interview for DSM-IV - Patient Edition (SCID-P; First et al. 1995). All subjects were required to have their major depression in clinical remission and to show marked improvement in overall functioning for at least 3 months of antidepressant treatment, as reported by the patient. All subjects were also required to have a score lower or equal to 8 on the modified 25-item Hamilton Rating Scale for Depression (HRSD-25; Hamilton 1967). All enrolled subjects were concurrently treated with an SSRI. During the SCID-P interview, information was gathered about the number of prior episodes of major depression and the type of response pattern to the SSRI (i.e., "true drug" response when delayed and persistent vs "placebo pattern" when early and/or a history of non-persistent response to medication). This information was checked with the medical records.

At the time of enrollment, subjects provided written informed consent after the nature and the procedure of the study had been fully explained. To rule out medical and neurological illness, the subjects underwent complete physical examination, including ECG and laboratory tests.

\section{Tryptophan depletion}

In order to achieve a $90 \%$ reduction of tryptophan levels, the experimental session included a $24-\mathrm{h}$ low tryptophan $(160 \mathrm{mg}$ /day) diet followed by a second day on which a tryptophan-free amino acid (AA) drink along with 25 AA capsules were administered. The AA drink contained L-alanine $5.5 \mathrm{~g}$, L-phenylalanine $5.7 \mathrm{~g}$, L-proline $12.2 \mathrm{~g}$, L-lysine monohydrochloride $11.0 \mathrm{~g}$, glycine $3.2 \mathrm{~g}$, L-serine $6.9 \mathrm{gm}$, L-histidine $3.2 \mathrm{~g}$, L-threonine $6.9 \mathrm{~g}$, L-isoleucine $8.0 \mathrm{~g}$, L-tyrosine $6.9 \mathrm{~g}$, L-leucine $13.5 \mathrm{~g}$, and L-valine $8.9 \mathrm{~g}$. The AA drinks were prepared under the direction of a research dietitian by mixing the above AA powder with water for a final volume of $350 \mathrm{ml}$ and flavored to taste with Hershey's chocolate syrup. Subjects drank the solution through a straw. Three amino acids were not included in the drink because of their unpleasant taste and were administered in 25 capsules immediately after the drink. The capsules contained a total dosage of $10.55 \mathrm{~g}$ with the following distribution of amino acids: L-methionine $3.0 \mathrm{~g}$, L-arginine $4.90 \mathrm{~g}$, and L-cysteine $2.65 \mathrm{~g}$.

The control session (aimed at leading to a $10-20 \%$ reduction of tryptophan levels) followed the procedure described by Krahn et al. (1996). A 24-h $160 \mathrm{mg} /$ day tryptophan diet was followed the next morning by a $350-\mathrm{ml}$ AA drink and 25 capsules. The drink and capsules contained the same amino acids as in the active challenge condition, but only $25 \%$ of their weight.

\section{Behavioral ratings}

Subjects were continually monitored during the day of their tests by trained clinicians and research assistants. All raters were blind to the sequence of testing. Behavioral ratings consisted of the modified 6-item version of the original 17-item Hamilton Rating Scale for Depression (HRSD-6; Bech et al. 1981) and the Hamilton Rating Scale for Anxiety (HRSA; Hamilton 1959). The item regarding insomnia was excluded from the HRSA. Furthermore, the following self-rated scales were administered: the Symptom Questionnaire (SQ; Kellner 1987) and the Anger Attacks Questionnaire (Fava et al. 1991).

\section{Procedure}

TD was conducted in a double-blind, controlled, balanced, crossover fashion. On the first day of the study, subjects arrived at the General Clinical Research Center of the Massachusetts General Hospital after fasting overnight. Following plasma collection and ratings, patients left the hospital with a low-tryptophan diet to take home. The low-tryptophan diets were designed by a research dietitian and were composed of regular food low in tryptophan, containing 2,300 calories. During the diets, all patients consumed a cookie which either contained $0.0003 \mathrm{~g}$ tryptophan (prior to the depletion challenge) or $0.0484 \mathrm{~g}$ tryptophan (prior to the control challenge).

On day 2 of the study, subjects arrived at the center after an overnight fast for either a TD session or a control session. Ratings, blood sampling, and vital signs were performed and this was followed by the ingestion of the AA drink and capsules 30 min later. Subjects remained in a private room of the center for the next $7 \mathrm{~h}$ but were free to walk about the room, use the toilet, and drink water. They continued to fast throughout the day until the test was completed, when they returned to regular food intake.

Behavioral ratings were obtained at day 1 prior to starting the diet, at day 2 prior to ingestion of the AA drink, as well as 5 and $7 \mathrm{~h}$ after ingestion. Ratings were obtained again in the morning of day 3 , when adverse events were also recorded. At all these time points, blood samples for measurement of free and total tryptophan (Trp) and large neutral amino acids (LNAAs) were obtained. Within 5-8 days after the first session, patients underwent the second challenge, using an identical procedure. Subjects were compensated up to $\$ 160$.

\section{Tryptophan measurement}

Total plasma tryptophan level was measured by high-performance liquid chromatography with fluorometric detection. Free plasma tryptophan was assayed by obtaining the ultrafiltrate of plasma from cellulose-based filters and subjecting the ultrafiltrate to the high-performance liquid chromatography with fluorometric detection method.

\section{Data analyses}

A patient was considered a "responder to TD" if the increase in HRSD-6 scores was at least $50 \%$ and at least three points. The rationale for this criterion comes from a study by O'Sullivan et al. (1997); three points increase on the HRSD-6 is approximately half of the difference between depressed patients before and after treatment. The relationship between pattern of response and response to TD was examined using $\chi^{2}$ analysis. Results from behavioral and biochemical ratings were also analyzed by means of a two (session: TD/control) $\times$ two (time: pre/postmeasurement) repeated measures analysis of variance. The relationship among changes in depression scores and biochemical measures was investigated by calculating correlations among residualized change scores. To investigate the influence of number of episodes and duration of remission, correlations were calculated between these variables and the change in symptom scores. One case with an extreme number of episodes (40) was a univariate outlier. For the statistical analysis, this variable was recoded as 10 .

\section{Results}

Description of sample, drop-outs, and side-effects

Of the 17 subjects who entered the study, 15 completed at least one challenge test, and 10 subjects completed the study protocol. The two patients who did not complete 
Table 1 Sample characteristics and main results. Depression scores refer to Hamilton Depression Rating Scale, six-item version, scores on day 2 at 9 a.m. (Pre) and at 4 p.m. (Post), and on day 3 at 11 a.m. (Fu). Remis. Duration of remission (months), Epis. number of depressive episodes, Medication type and dosage of medication, Pattern response pattern to selective serotonin reuptake inhibitor (SSRI), Responder fulfills criteria of responder to tryptophan depletion (TD) challenge, $\triangle T R P$ reduction of ratio free tryptophan/large neutral amino acids at 4 p.m. compared to 9 a.m., both on day 2

\begin{tabular}{|c|c|c|c|c|c|c|c|c|c|c|c|c|c|c|c|}
\hline \multicolumn{8}{|c|}{ Baseline characteristics } & \multicolumn{4}{|c|}{ TD challenge } & \multicolumn{4}{|c|}{ Control challenge } \\
\hline \multirow[t]{2}{*}{ Number } & \multirow[t]{2}{*}{ Sex } & \multirow[t]{2}{*}{$\begin{array}{l}\text { Age } \\
\text { (years) }\end{array}$} & \multirow[t]{2}{*}{ Remis. } & \multirow[t]{2}{*}{ Epis. } & \multirow[t]{2}{*}{ Medication } & \multirow[t]{2}{*}{ Pattern } & \multirow[t]{2}{*}{ Responder } & \multicolumn{3}{|c|}{$\begin{array}{l}\text { Depression } \\
\text { scores }\end{array}$} & \multirow[t]{2}{*}{$\begin{array}{l}\Delta \mathrm{TRP} \\
\text { Post }\end{array}$} & \multicolumn{3}{|c|}{$\begin{array}{l}\text { Depression } \\
\text { scores }\end{array}$} & \multirow[t]{2}{*}{$\begin{array}{l}\Delta \mathrm{TRP} \\
\text { Post }\end{array}$} \\
\hline & & & & & & & & Pre & Post & $\mathrm{Fu}$ & & Pre & Post & $\mathrm{Fu}$ & \\
\hline 1 & M & 51 & 36 & 1 & Fluoxetine 40 & True & Yes & 2 & 5 & 1 & 89.6 & 1 & 0 & 0 & 17.8 \\
\hline 2 & $\mathrm{~F}$ & 55 & 30 & 1 & Sertraline 100 & True & No & 1 & 2 & 1 & a & 1 & 0 & 0 & $\mathrm{a}$ \\
\hline 3 & $\mathrm{~F}$ & 57 & 22 & 40 & Fluoxetine 100 & Placebo & No & 1 & 2 & 2 & 41.9 & 5 & 3 & 0 & 85.0 \\
\hline 4 & $\mathrm{~F}$ & 40 & 11 & 1 & Fluoxetine 40 & True & Yes & 0 & 7 & 3 & 87.9 & 0 & 1 & 1 & 29.9 \\
\hline 5 & $\mathrm{~F}$ & 29 & 4 & 5 & Sertraline 200 & True & Yes & 0 & 4 & 1 & 93.2 & 1 & 0 & 6 & 43.0 \\
\hline 6 & $\mathrm{~F}$ & 50 & 4 & 6 & Venlafaxine 300 & True & Yes & 4 & 10 & 11 & 94.3 & 1 & 3 & 2 & 79.0 \\
\hline 7 & M & 40 & 5 & 2 & Paroxetine 20 & Placebo & Yes & 0 & 5 & 0 & 90.7 & 1 & 0 & 2 & 20.2 \\
\hline 8 & $\mathrm{~F}$ & 47 & 7 & 1 & Fluoxetine 20 & Placebo & No & 1 & 1 & 0 & 90.7 & 0 & 0 & 0 & 76.3 \\
\hline 9 & $\mathrm{~F}$ & 54 & 5 & 6 & Paroxetine 60 & True & Yes & 1 & 10 & 8 & 88.5 & 4 & 3 & 5 & 22.9 \\
\hline 10 & $\mathrm{M}$ & 27 & 3 & 6 & Fluoxetine 40 & True & No & 1 & 1 & 2 & 64.1 & 0 & 0 & 0 & 12.1 \\
\hline Mean & & 45.0 & 6.9 & 12.7 & & & & 1.1 & 4.7 & 2.9 & 82.3 & 1.4 & 1.0 & 1.6 & 42.9 \\
\hline SD & & 10.7 & 11.9 & 12.2 & & & & 1.2 & 3.4 & 3.7 & 17.7 & 1.7 & 1.4 & 2.2 & 29.3 \\
\hline
\end{tabular}

${ }^{a}$ Lost to data analysis because of interfering peak in sample

Table 2 Biochemical changes during TD and control challenge ( $n=10)$. Note: $n=9$ for free tryptophan (TRP) and free TRP/large neutral amino acids (LNAA)

\begin{tabular}{|c|c|c|c|c|c|c|c|}
\hline & \multicolumn{3}{|l|}{ TD challenge } & \multicolumn{3}{|c|}{ Control challenge } & \multirow{2}{*}{$\begin{array}{l}\text { Significance } \\
\text { of the } \\
\text { interaction } \\
\text { term }\end{array}$} \\
\hline & $\begin{array}{l}\text { Day } 2, \\
9 \text { a.m. } \\
\text { Mean } \pm \text { SD }\end{array}$ & $\begin{array}{l}\text { Day 2, } \\
4 \text { p.m. } \\
\text { Mean } \pm \text { SD }\end{array}$ & $\begin{array}{l}\text { Percentage } \\
\text { change } \\
\text { Mean } \pm \text { SD }\end{array}$ & $\begin{array}{l}\text { Day } 2, \\
9 \text { a.m. } \\
\text { Mean } \pm \text { SD }\end{array}$ & $\begin{array}{l}\text { Day 2, } \\
4 \text { p.m. } \\
\text { Mean } \pm \text { SD }\end{array}$ & $\begin{array}{l}\text { Percentage } \\
\text { change } \\
\text { Mean } \pm \text { SD }\end{array}$ & \\
\hline Total TRP (nM/ml) & $32.1 \pm 7.4$ & $10.3 \pm 7.0$ & $-67.9 \pm 20.7$ & $33.0 \pm 5.6$ & $21.0 \pm 9.8$ & $-42.0 \pm 20.3$ & 0.074 \\
\hline Free TRP $(\mathrm{nM} / \mathrm{ml})$ & $5.0 \pm 1.0$ & $1.7 \pm 1.1$ & $-67.4 \pm 18.4$ & $5.9 \pm 2.1$ & $3.6 \pm 1.2$ & $-33.7 \pm 27.3$ & 0.386 \\
\hline Total TRP/LNAA ratio & $0.076 \pm 0.013$ & $0.013 \pm 0.012$ & $-82.1 \pm 18.9$ & $0.073 \pm 0.011$ & $0.037 \pm 0.019$ & $-52.6 \pm 23.7$ & 0.037 \\
\hline Free TRP/LNAA ratio & $0.012 \pm 0.003$ & $0.002 \pm 0.002$ & $-82.3 \pm 17.7$ & $0.013 \pm 0.006$ & $0.006 \pm 0.002$ & $-42.9 \pm 29.3$ & 0.240 \\
\hline
\end{tabular}

Table 3 Behavioral changes during tryptophan depletion and control challenge $(n=10)$. HAM-D6 Hamilton Depression Rating Scale, six-item version, $H A M-A$ Hamilton Anxiety Rating Scale, $S Q$ Symptom Questionnaire

\begin{tabular}{|c|c|c|c|c|c|c|c|}
\hline & \multicolumn{3}{|l|}{ TD challenge } & \multicolumn{3}{|c|}{ Control challenge } & \multirow{2}{*}{$\begin{array}{l}\text { Significance } \\
\text { of the } \\
\text { interaction } \\
\text { term }\end{array}$} \\
\hline & $\begin{array}{l}\text { Day 2, } 9 \text { a.m. } \\
\text { Mean } \pm \text { SD }\end{array}$ & $\begin{array}{l}\text { Day 2, } 4 \text { p.m. } \\
\text { Mean } \pm \text { SD }\end{array}$ & $\begin{array}{l}\text { Difference } \\
\text { Mean } \pm \text { SD }\end{array}$ & $\begin{array}{l}\text { Day 2, } 9 \text { a.m. } \\
\text { Mean } \pm \text { SD }\end{array}$ & $\begin{array}{l}\text { Day 2, } 4 \text { p.m. } \\
\text { Mean } \pm \text { SD }\end{array}$ & $\begin{array}{l}\text { Difference } \\
\text { Mean } \pm \text { SD }\end{array}$ & \\
\hline HAM-D6 & $1.1 \pm 1.2$ & $4.7 \pm 3.4$ & $3.6 \pm 3.1$ & $1.4 \pm 1.7$ & $1.0 \pm 1.4$ & $-0.4 \pm 1.2$ & 0.002 \\
\hline HAM-A & $2.2 \pm 1.5$ & $7.4 \pm 6.6$ & $5.2 \pm 6.4$ & $2.5 \pm 3.0$ & $1.9 \pm 2.2$ & $-0.6 \pm 3.5$ & 0.039 \\
\hline SQ depression & $2.5 \pm 2.5$ & $6.7 \pm 5.1$ & $4.2 \pm 4.4$ & $3.8 \pm 3.7$ & $3.2 \pm 3.0$ & $-0.6 \pm 2.4$ & 0.031 \\
\hline SQ anxiety & $2.9 \pm 3.9$ & $5.9 \pm 6.6$ & $3.0 \pm 3.9$ & $2.3 \pm 3.9$ & $2.2 \pm 4.6$ & $-0.1 \pm 1.4$ & 0.032 \\
\hline SQ anger & $1.3 \pm 1.4$ & $3.1 \pm 3.7$ & $1.8 \pm 3.6$ & $1.5 \pm 2.3$ & $2.5 \pm 3.4$ & $1.0 \pm 3.7$ & 0.502 \\
\hline SQ somatic & $4.5 \pm 4.1$ & $8.8 \pm 5.8$ & $4.3 \pm 5.6$ & $5.7 \pm 4.9$ & $4.3 \pm 4.9$ & $-1.4 \pm 4.6$ & 0.011 \\
\hline
\end{tabular}

one session were one female patient whose HRSD-25 score had suddenly increased to 19 on the morning of day 1 of the first session (control). The next morning the score was still 13, so this subject no longer fulfilled inclusion criteria. One male patient had to unexpectedly leave town before the study started. Of the remaining five drop-outs, one female patient showed symptoms of an anxiety attack during the first blood drawing on day 2 of the first (control) challenge. Three patients (two fe- males) completed the first session (two depletion, one control) but withdrew before the second session because of the side-effects. One female patient completed the first session and withdrew on the morning of day 2 of the second session (control) because of side-effects. Notable side-effects during the tests were nausea, vomiting, headaches, diarrhea, anxiety attack prior to blood drawing, hot and cold flushes, and faintness. Further sample characteristics are listed in Table 1. 


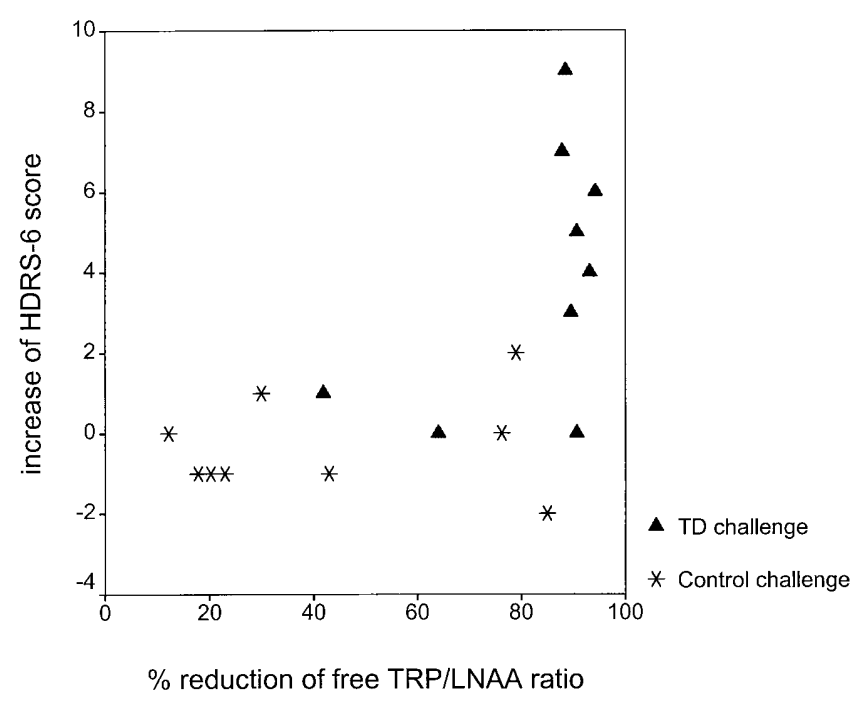

Fig. 1 Plot of behavioral and biochemical changes during both challenges. Note: each patient appears twice in this plot. HDRS-6 Six-item Hamilton Depression Rating Scale, TD tryptophan depletion, TRP/LNAA tryptophan/large neutral amino acid

\section{Biochemical effects of TD and the control procedure}

Table 2 shows that the TD procedure was successful in markedly lowering the ratio Trp/LNAA ( $82 \%$ reduction). However, due to an unexpected large reduction of Trp levels in the control condition, not all differences between the two conditions were significant. As can be seen in Table 1, one subject even showed a higher reduction in the control than in the TD session. All data were re-checked, but no coding errors were detected.

\section{Behavioral effects of TD and the control procedure}

Tables 1 and 3 summarize the behavioral effects of both challenges. The increase in scores on the HRSD-6, HRSA, SQ Anxiety, and SQ Somatic Symptoms was significantly higher during TD than during the control challenge. Patients therefore reported during the TD session a significant emergence of depression, anxiety, and somatic symptoms compared to the control session, but not more anger.

\section{Predictors of the effect of TD}

Although more patients with a history of true drug response pattern to the SSRIs fulfilled the definition of responder to TD (five out of seven: 71\%) than patients with a placebo response pattern (one out of three: $33 \%$ ), this difference failed to reach statistical significance $\left[\chi^{2}(1)=1.3, P=0.26\right]$. All correlations among residualized change scores (of changes in depression and biochemical measures) were non-significant. The same held true for the correlations between symptom changes and duration of remission and number of episodes.
The unexpected high reduction of tryptophan levels during the control session prompted us to take a closer look at the dose-response relationship between change in mood scores and reduction of tryptophan levels. Figure 1 suggests that there is no linear or curvilinear doseresponse curve, but rather a threshold. All patients who showed symptom changes had at least an $80 \%$ reduction of Trp/LNAA ratio. This was examined further using receiver operating characteristic (ROC) analysis. The ROC curve is a measure of accuracy of a diagnostic test (Metz 1978). Using our predetermined criteria of HRSD change scores to categorize patients as "actually positive" or "actually negative", this analysis showed that a threshold of $88.2 \%$ reduction of free Trp/LNAA predicts response to TD with a sensitivity of 0.84 and a specificity of 0.76 . The area under the curve is $0.84(\mathrm{SD}=0.18)$. When the data from the placebo condition are included, sensitivity rises to 0.92 , specificity to 0.82 , and the area under the curve is 0.95 ( $\mathrm{SD}=0.05$ ). It should be noted, however, that these solutions are extremely unstable given the low number of subjects.

\section{Discussion}

This study confirmed that TD was significantly related to a worsening of mood in SSRI-treated, remitted depressed patients. In view of a number of recent negative studies (Aberg-Wistedt et al. 1998; Moore et al. 1998), this replication is relevant. Furthermore, TD was associated with an increase in anxiety and somatic symptoms, but not with increase in anger. One patient who was on venlafaxine, which is active at both the serotonergic and noradrenergic system, responded to TD. This result is of note because responders to the noradrenergic antidepressant desipramine are not vulnerable to relapse after TD (Delgado et al. 1999).

The substantial reduction of Trp levels that were obtained in the control session was unexpected and unintended, but has some important implications. Despite a $43 \%$ reduction of Trp levels, no behavioral effects occurred during the control session. This serendipitous finding is important in the light of the negative or partly negative findings mentioned above (Bremner et al. 1997; Aberg-Wistedt et al. 1998; Moore et al. 1998). Lack of effect in these studies may well be due to insufficient depletion of tryptophan, since the level of Trp reduction that was obtained $(57.5 \%$, $44.6 \%$, and $52 \%$, respectively) hardly exceeds the reduction during the control session in the present study. The present data, combined with those of previous studies (see Van der Does 2000b), provide some evidence that the dose-response curve of TD is not linear, and that a threshold exists that needs to be exceeded before behavioral effects occur. In view of the fact that the body has compensatory reactions to many changes, it may come as no surprise that the reduction of tryptophan needs to be substantial before behavioral effects are measurable.

Except for "magnitude of Trp reduction", the present study did not identify new predictors or mediators of the 
effects of TD on mood. An important limitation of the study is the small sample size. However, duration of remission and number of episodes do not emerge from this study as promising candidates. This does not hold true for history of response pattern to antidepressant medication. Although the trend was far from significant, this variable deserves further investigation. In summary, this study confirms the mood-lowering effects of TD in a subgroup of SSRI-treated, formerly depressed individuals. Recent negative findings may have been caused by insufficient lowering of Trp levels.

Acknowledgements This study was supported by NIH grant M01-RR0-1066 to the General Clinical Research Center of the Massachusetts General Hospital. Dr. Spillmann acknowledges support by grants from the foundations "EMDO," "Helmut Horten," and "Theodor und Ida Herzog Egli" in Switzerland. The foundations "Prins Bernhard Fonds" and "De Drie Lichten" in The Netherlands supported Dr. Van der Does' stay in the United States. We thank the GCRC nutrition staff for their extremely valuable contribution and John Vetrano from the research pharmacy for his help with the randomization.

\section{References}

Aberg-Wistedt A, Hasselmark L, Stain-Malmgren R, Aperia B, Kjellman BF, Mathe AA (1998) Serotonergic 'vulnerability' in affective disorder. Acta Psychiatr Scand 97:374-380

Bech P, Allerup P, Gram LF et al. (1981) The Hamilton Depression Scale. Acta Psychiatr Scand 63:290-299

Biggio G, Fadda F, Fanni P, Tagliamonte A, Gesse GL (1974) Rapid depletion of serum tryptophan, brain tryptophan, serotonin and 5-hydroxyindoleacetic acid by a tryptophan-free diet. Life Sci 14:1321-1329

Bremner DJ, Innis RB, Salomon RM, Staib LH, Ng CK, Miller HL et al. (1997) Positron emission tomography measurement of cerebral metabolic correlates of tryptophan depletioninduced depressive relapse. Arch Gen Psychiatry 54:364374

Carpenter LL, Anderson GM, Pelton GH, Gudin JA, Kirwin PD, Price LH et al. (1998) Tryptophan depletion during continuous CSF sampling in healthy human subjects. Neuropsychopharmacology 19:26-35
Delgado PL, Charney DS, Price LH, Aghajanian GK, Landis H, Heninger GR (1990) Serotonin function and the mechanism of antidepressant action. Arch Gen Psychiatry 47:411-418

Delgado PL, Price LH, Miller HL, Salomon RM, Licinio J, Krystal JH et al. (1991) Rapid serotonin depletion as a provocative challenge test for patients with major depression. Psychopharmacol Bull 27:321-330

Delgado PL, Miller HL, Salomon RM, Licinio J, Krystal JH, Moreno FA, Heninger GR, Charney DS (1999) Tryptophandepletion challenge in depressed patients treated with desipramine of fluoxetine. Biol Psychiatry 46:212-220

Fava M, Rosenbaum JF, McCarthy MK, Pava J, Steingard RJ, Bless E (1991) Anger attacks in depressed outpatients and their response to fluoxetine. Psychopharmacol Bull 27:275279

First MB, Spitzer RL, Gibbon M, Williams JBW (1995) Structured clinical interview for DSM-IV axis I disorders. Patient edition (SCID-I/P). Biometrics Research Department, NYSPI, New York

Hamilton M (1959) The assessment of anxiety states by rating. Br J Med Psychol 32:50-55

Hamilton M (1967) Development of a rating scale for primary depressive illness. Br J Soc Clin Psychol 6:278-296

Kellner RA (1987) A symptom questionnaire. J Clin Psychiatry 48:268-274

Krahn LE, Lu PY, Klee G, Delgado PL, Lin SC, Zimmerman RC (1996) Examining serotonin function. Neuropsychopharmacology 15:325-328

Leyton M, Young SN, Benkelfat C (1997) Relapse of depression after rapid depletion of tryptophan (letter). Lancet 349:18401841

Metz CE (1978) Basic principles of ROC analysis. Semin Nucl Med 8:283-298

Moore P, Gillin C, Bhatti T, DeModena A, Seifritz E, Clark C et al. (1998) Rapid tryptophan depletion, sleep electroencephalogram, and mood in men with remitted depression on serotonin reuptake inhibitors. Arch Gen Psychiatry 55:534-539

O’Sullivan RL, Fava M, Agustin C, Baer L, Rosenbaum JF (1997) Sensitivity of the six-item Hamilton depression rating scale. Acta Psychiatr Scand 95:379-384

Smith KA, Fairburn CG, Cowen PJ (1997) Relapse of depression after rapid depletion of tryptophan. Lancet 349:915-919

Van der Does AJW (2000a) The effects of tryptophan depletion on mood and psychiatric symptoms: review. J Affect Disord (in press)

Van der Does AJW (2000b) Tryptophan depletion and mood: possible explanation for discrepant findings (letter). Arch Gen Psychiatry (in press) 